\title{
Antidepressant Pharmacotherapy - Do the Benefits Outweigh the Risks?
}

\author{
Angela Getz, Fenglian $\mathrm{Xu}$ and Naweed Syed \\ University of Calgary, Faculty of Medicine, Department of Cell Biology and Anatomy, \\ Hotchkiss Brain Institute \\ Canada
}

\section{Introduction}

Major depressive disorder (MDD) is a debilitating and often recurrent psychiatric illness that impacts the lives of millions. Approximately 20 percent of individuals will experience at least one depressive episode during their lives, and the high rates of chronic morbidity (depressive episodes typically last for several months) and mortality (owing to suicide) attributed to this disorder constitute one of the largest global economic disease burdens (Kessler et al., 2005). Despite the considerable burden of depression, our understanding of its pathophysiology and the therapeutic mechanisms of action of antidepressant drugs remains incomplete. In fact, much of what we currently understand about the neuropathology of depression is derived from the observed effects of known antidepressants on the brain. This situation is confounded by the fact that currently available antidepressant drugs are of limited clinical efficacy - the antidepressant response typically takes several weeks to develop, and a substantial proportion of patients do not experience a significant improvement in depressive symptoms, or full clinical remission. Furthermore, because antidepressant efficacy varies significantly as a function of symptom severity, the benefit of antidepressant therapy may be limited or nonexistent in patients with mild to moderate depressive symptoms, which represent the majority of clinical cases (Fournier et al., 2010). When the inadequate efficacy profiles of antidepressant drugs are weighed against our limited understanding of depression, the therapeutic action of antidepressants, and the potential negative side effects of these drugs arising from nonspecific actions, a difficult question arises: do the benefits of antidepressant pharmacotherapy outweigh the risks?

In this chapter, we explore the development of the current theories of depression etiology, the hindrances of current antidepressant therapeutics, and how the poor understanding of the mechanism of antidepressant action contributes to a haphazard interpretation of the benefits and consequences arising from their non-specific interactions. Through the use of a simple single-synapse experimental approach, we have gained insights into the impact of non-specific antidepressant actions on neuronal function, and our findings will be discussed in this context. Finally, we will explore prospective developments in the field of depression pharmacotherapy that may hold the potential to revolutionize the way we understand and treat depression. 


\subsection{Identifying \& understanding depression}

Depression is a prevalent psychiatric condition in which the depressive affect (the immediate emotional state and a normal emotional response) becomes sustained and predominant, thus constituting a disorder of mood (a sustained emotional state). It is characterized by persistent emotional symptoms including a dysphoric mood and anhedonia (loss of interest or pleasure), low self-esteem, feelings of guilt, anguish, apathy and pessimism, and thoughts of suicide or death. Additional biological symptoms include difficulty concentrating and remembering, disturbances of sleep and appetite, loss of energy and libido, and psychomotor agitation (restlessness) or psychomotor retardation (slowing of thoughts and actions). The clinical diagnosis of depression is subjective, being based on the concurrent presence of a depressed mood, and a number of the above-mentioned biological symptoms, for a period of at least two weeks.

Because the understanding of the pathophysiology of depression is limited, reliable indicators of risk have not yet been identified. The multitude of symptom profiles that constitute a diagnosis of depression points to the heterogeneous nature of the disorder, and its probable multifactorial and polygenic etiology. Indeed, the heterogeneity of depression is evident in the markedly different occurrence of depressive symptoms, genetic predispositions, and environmental risk factors such as stressful life events, among patients that present with MDD. Depression has a strong genetic predisposition, with an estimated heritability of 40 percent (Krishnan \& Nestler, 2008; Sullivan et al., 2000); and while genetic association studies have identified some MDD susceptibility genes, several of which play a role in monoaminergic neurotransmission and neuroplasticity, findings have often been inconsistent, and the role of genetic polymorphisms in the manifestation of MDD remains uncertain (López-León et al., 2008; Pezawas et al., 2008). The roles of monoamine neurotransmitters and neuroplasticity in depression will be further explored below.

The linear relationship between genetic mutations and inherited disorders, which has proven useful in understanding numerous other conditions (such as familial Alzheimer's disease or Huntington's disease), is not so evident in psychiatric disorders, where it is likely that complex interactions between genes and the environment influence neuronal networks, and ultimately behaviour. A polymorphism in the serotonin transporter (5-HTT) gene, which modulates serotonergic neurotransmission, was found to influence the occurrence of depression in response to stressful life events, providing the first direct evidence for the interplay of genes and the environment in the etiology of depression (Caspi et al., 2003). The strong contribution of both genetics and the environment to MDD provides a feasible starting point from which we can begin to understand and interpret the heterogeneity of depression, and ultimately, perhaps, even predict or prevent its onset.

\subsection{Depression etiology: Insights from antidepressant drugs}

Advances in understanding the etiology and developing effective therapeutics for MDD and numerous psychiatric and neurodegenerative illnesses, for that matter - have lagged considerably behind other areas of medical research, the primary obstacle being the inherent complexity of the human brain. Research in the field of mood disorders has been hindered by both the difficulty of studying the brain directly (though modern imaging techniques have enabled considerable progress in this area), and the lack of truly representative animal models, where, while biological correlates of the disorder can be induced in animal models, the emotional and psychological characteristics that define the human condition are far from accurately paralleled. 
The mechanistic understanding of both MDD and the therapeutic mode of action of antidepressants has been slow to follow the development and clinical application of antidepressant medication, particularly because the desired outcome of drug treatment is readily apparent as an elevation of mood and alleviation of depressive symptoms, whereas reversal of the causative brain abnormalities underlying MDD, such as neurochemical imbalance and/or structural alterations, are not so evident. A case in point, the primary theories of the etiology of depression have developed not from identifying the factors that underlie the neuropathology of MDD, but rather from observing the effects of antidepressant drugs on the brain and interpreting the roles of these target neuronal systems in behaviour.

\subsubsection{The monoamine hypothesis}

The monoaminergic theory of depression posits that the cause of depression is a functional deficit in monoaminergic neurotransmission, due to the decreased availability of monoamine neurotransmitters, of which serotonin (5-Hydroxytryptamine; 5-HT) has received considerable attention in depression. Developed from early observations that drugs fortuitously discovered to exert antidepressant effects all appeared to target monoaminergic systems, the monoamine hypothesis was the first biochemical theory of depression, and remains one of the main etiological hypotheses of the disorder (Schildkraut, 1965; Lapin et al., 1969). Serotonin in particular plays a dynamic role in the regulation of mood, cognition, attention, learning, appetite, sleep, motor function and the response to stress (Martinowich \& Lu, 2008; Oberlander et al., 2009). In accordance with the monoamine hypothesis, there is an obvious parallel between the symptomatic disruption of mood and behaviour in depression, and the normal physiological role of serotonin.

The monoamine theory of MDD provides the most logical basis for understanding the therapeutic mode of action of antidepressant drugs, as nearly all available antidepressants act by potentiating the synaptic availability of monoamine neurotransmitters (López-Muñoz \& Alamo, 2009), which will be further explored below. Whereas antidepressants produce a rapid biochemical effect and an almost immediate enhancement of chemical neurotransmission, there is a substantial delay in the onset of antidepressant action. Achieving clinical improvement in depressive symptoms requires several weeks of continuous antidepressant administration, highlighting two obvious limitations of both current antidepressant medications and the monoamine theory of depression: firstly, the prolonged period of therapeutic inefficacy provides a large window during which depressive symptoms remain untreated, and suicide risk is high (Licinio \& Wong, 2005); and secondly, such a delay in the onset of antidepressant action indicates that the cause of depression is not simply a deficit of monoamine neurotransmitters.

\subsubsection{The Neuroplasticity hypothesis}

A recent neuroplasticity theory of MDD gaining acceptance and substantial evidentiary support posits that depression results from disruptions of neuronal plasticity (structural and functional alterations of the brain in response to environmental changes) at various regions of the brain (Pittenger \& Duman, 2008). In depressed patients, post-mortem and neuroimaging studies have identified neuronal atrophy and aberrant activity patterns in several brain structures, most notably in the prefrontal cortex, hippocampus and amygdala (Zou et al., 2010; Drevets, 2001; Krishnan \& Nestler, 2008). Remarkably, chronic stress, an 
environmental risk factor known to contribute to the development depression, also affects neuroplasticity in similar brain regions. These affected structures are responsible for various aspects of cognition, including executive functions (prefrontal cortex), emotional response (amygdala) and memory formation (hippocampus). Again, the normal functions of the brain regions disrupted by chronic stress and MDD parallel the symptomatology of depression, pointing to an underlying role for dysfunctional neuronal plasticity in the etiology of MDD. A powerful facet of the neuroplastic hypothesis is the ability to explain the delayed onset of antidepressant drug effects. Through a slower-acting secondary neuroplastic mechanism, long-term adaptive changes in the brain in response to antidepressants are thought to be responsible for the clinical improvement of depressive symptoms. Indeed, following chronic antidepressant treatment, the occurrence of structural and functional changes and enhanced neurogenesis that normalize neuronal networks and activity patterns correlates with the onset of the therapeutic response, and are likely to play a causal role in antidepressant action (Ressler \& Mayberg, 2007; Santarelli et al., 2003; Maya Vetencourt et al., 2008). Though we lack a clear understanding of the mechanistic action of antidepressants, there is an apparent relationship between the mechanisms of neuroplasticity and MDD neuropathology, which has been illuminated by the molecular and cellular changes in the brain brought about by antidepressant action. The implication of neuroplasticity in MDD lends to the exciting possibility that the cellular and molecular mechanisms of synaptic plasticity may be effective and more direct targets for antidepressant therapeutics, providing prospective directions for investigation in a field of pharmacology that has been stagnant for decades.

\subsubsection{Linking monoamines, neuroplasticity \& antidepressants}

The slow onset of therapeutic effects of antidepressant drugs that rapidly increase synaptic levels of monoamine neurotransmitters necessitated the development of an alternative neuromodulatory hypothesis for the mechanism of therapeutic action of antidepressant medication. However, the monoaminergic and neuroplasticity theories of depression are not mutually exclusive, as monoamines are modulatory neurotransmitters that influence neurogenesis and neuron survival, neuronal activity, synaptogenesis and synaptic plasticity by initiating molecular signalling cascades. In particular, changes in the expression levels or function of neurotrophic factors, such as brain-derived neurotrophic factor (BDNF), a growth factor that is a key regulator of synaptic plasticity and participates in a developmental feed-back loop with serotonin, has been suggested to underlie both depression neuropathology and the therapeutic antidepressant response (Martinowich \& $\mathrm{Lu}, 2008)$. Studies demonstrating that levels of BDNF and BDNF-mediated signalling are reduced in depressed patients and increased patients receiving antidepressant medication provide a link between the expression of BDNF and the therapeutic action of antidepressants (Shimizu et al., 2003; Chen, 2001). This notion is further supported by evidence that BDNF signalling is necessary for mediating the antidepressant response in animal models (Saarelainen et al., 2003). How exactly this BDNF-mediated neuroplasticity contributes to the emotional and behavioural response in antidepressant treatment remains unidentified.

The intracellular signal transduction cascades connecting serotonin neurotransmission and BDNF expression provide a workable explanation for the ability of antidepressants that potentiate monoaminergic activity to promote neuroplasticity and an antidepressant 
response. All but one of the 5-HT receptor subtypes act through a G-protein coupled metabotropic mechanism, which initiates cellular responses through the activation of intracellular signalling cascades. Chronic antidepressant treatment, presumably by promoting enhanced serotonergic synaptic availability and receptor signalling, has been found to up-regulate numerous components of the cAMP signal transduction pathway, including the effector protein kinase A (PKA) and the transcription factor cAMP-responseelement-binding protein (CREB) (Nestler et al., 1989; Nibuya et al., 1996; Pittenger \& Duman, 2008). Notably, the cAMP-PKA-CREB cascade, which is implicated in synaptic plasticity, is downstream of a number stimulatory G-protein coupled receptors, including several serotonin receptor subtypes (Martinowich \& Lu, 2008). As CREB is a key transcription factor involved in activity-dependent BDNF expression (Tao et al., 1998), the activation of CREB may be one of the mechanisms by which the antidepressant-induced elevation of monoamines acts to enhance BDNF expression and promote neuroplasticity.

\subsection{Antidepressant pharmacotherapy: Limited options \& limited outcomes}

Nearly all currently marketed antidepressant medications act to increase the synaptic availability of monoamine neurotransmitters. This is achieved through one of two mechanisms: the prevention of degradation by inhibition of the enzyme monoamine oxidase, or the prevention of re-uptake from the synapse by inhibition of the reuptake transporter proteins. The three commonly prescribed classes of antidepressants include the Monoamine oxidase inhibitors (MAOIs), the tricyclic antidepressants (TCA), and the selective reuptake inhibitors (SRIs), including selective serotonin reuptake inhibitors (SSRIs), and serotonin-norepinephrine reuptake inhibitors (SNRIs).

MAOIs: Among the first clinically introduced antidepressants, MAOIs cause inhibition of the monoamine oxidase enzyme, which acts to degrade serotonin, norepinephrine and dopamine. In the brain, monoamine oxidase (MAO) regulates the cytoplasmic concentration of monoamine neurotransmitters, thus, the primary effect of MAOIs is to increase the cytoplasmic concentration of monoamines, thereby promoting spontaneous transmitter leakage and enhanced synaptic action. The enzyme isoform MAO-A is the primary target of MAOI-type antidepressants, and is responsible for the antidepressant effect. However, most MAOIs are not particularly selective, inhibiting both MAO-A and MAO-B isoforms, as well as several other enzymes, including those involved in drug metabolism. These non-specific interactions contribute to an extensive profile of serious adverse effects including cardiovascular complications, dietary interactions, drug interactions, and lethality in overdose.

TCAs: Another class of early antidepressants, tricyclic compounds (so named for their characteristic three-ringed chemical structure) were initially synthesized as potential antipsychotic drugs, and though found ineffective in psychosis, they did exert potent antidepressive effects. TCAs act to inhibit the reuptake of monoamines from the synapse by blocking reuptake transporters, the primary mechanism by which the length of the synaptic signal is regulated and the actions of monoamine neurotransmitters are terminated. This action enhances the synaptic availability of monoamine neurotransmitters. All of the three major classes of monoamine transporter proteins, the serotonin transporter (SERT or 5HTT), the norepinephrine transporter (NET) and to a lesser extent the dopamine transporter (DAT), are inhibited by TCAs. As with MAOIs, the non-selective pharmacological profile of TCAs contributes to a host of unwanted effects, including inhibition of various types of 
neurotransmitter receptors, cardiovascular effects, sedation, drug interactions, and lethality in overdose.

SRIs: The diverse systemic side effect profiles of MAOIs and TCAs, coupled with the toxic effects in overdose that lead to the frequent use of these compounds in suicide attempts, prompted the development of new antidepressants that would be safer and more tolerable what resulted was a diverse class of second-generation reuptake inhibitors whose clinical use rapidly overtook that of MAOIs and TCAs. Of all the available types of antidepressant drugs, selective serotonin reuptake inhibitors (SSRIs) are the most commonly prescribed. Acting in a manner analogous to TCAs, these second generation compounds block monoamine reuptake, but exhibit selectivity for blocking SERT and/or NET. While the profile of adverse drug effects of SRIs is more favourable than that of MAOIs or TCAs, these antidepressants still exhibit considerable side effects including the nonspecific inhibition of ion channels and neurotransmitter receptors, and even, surprisingly, an increased risk of suicide.

\begin{tabular}{|c|c|c|c|}
\hline \multicolumn{2}{|c|}{ Drug Class } & Examples & Conventional Mode of Action \\
\hline \multicolumn{2}{|c|}{ MAOIs } & $\begin{array}{l}\text { Phenelzine } \\
\text { Rasagiline } \\
\text { Moclobemide } \\
\text { Iproniazid }\end{array}$ & $\begin{array}{l}\text { Monoamine Oxidase Inhibition } \\
\text { (MAO-A) }\end{array}$ \\
\hline \multicolumn{2}{|c|}{ TCAs } & $\begin{array}{l}\text { Imipramine } \\
\text { Amitriptyline } \\
\text { Doxepin } \\
\text { Desipramine }\end{array}$ & $\begin{array}{l}\text { Monoamine Reuptake Transporter } \\
\text { Inhibition (SERT, NET, DAT) }\end{array}$ \\
\hline \multirow[t]{2}{*}{ SRIs } & SSRI & $\begin{array}{l}\text { Fluoxetine } \\
\text { Paroxetine } \\
\text { Citalopram } \\
\text { Sertaline }\end{array}$ & $\begin{array}{l}\text { Selective Serotonin Reuptake } \\
\text { Inhibition (SERT) }\end{array}$ \\
\hline & SNRI & $\begin{array}{l}\text { Venlafaxine } \\
\text { Duloxetine }\end{array}$ & $\begin{array}{c}\text { Serotonin-Norepinephrine } \\
\text { Reuptake Inhibition (SERT, NET) }\end{array}$ \\
\hline
\end{tabular}

Table 1. Classification of monoaminergic antidepressant drugs according to the conventional mechanism of action.

The advent of second-generation SRIs with a superior safety profile improved the pharmacological management of depression; however, this advance was not paralleled by an improvement in the clinical outcome of MDD pharmacotherapy. MAOIs, TCAs, and SRIs all require several weeks of continuous treatment for an improvement of depressive symptoms to appear, meanwhile the response rate is abysmally low and the relapse rate is high. Only approximately 60 percent of patients receiving antidepressants experience a meaningful improvement of depressive symptoms, with as little as one third experiencing full remission (Trivedi et al., 2006; Thase et al., 2005). A further disadvantage of the available plethora of antidepressant medications is the fact that they all essentially work through the same monoaminergic mechanism. Thus, attempting combinatorial therapy or a series of different medications in attempts to gain improvement in the clinical management of MDD faces fundamental mechanistic limitations, though this is a commonly employed but largely unproven clinical strategy (Thase, 2011). Whereas SRIs have to some extent addressed the 
adverse side effect profile of antidepressants, the efficacy and time course of therapeutic action are two critical aspects of antidepressant therapeutics that still must be improved.

\subsection{Side effects of antidepressant pharmacotherapy: Consequences of high therapeutic doses \& non-specific drug effects}

Antidepressants are notoriously promiscuous substances, indiscriminately affecting a wide range of ion channels, neurotransmitter receptors, and synaptic plasticity mechanisms that ultimately results in changes in neuronal architecture and function. While these non-specific effects have been suggested to be essential for producing the antidepressant response, the fact that we do not know the mechanism of therapeutic action of antidepressants makes it difficult to separate the beneficial from the detrimental effects of these non-specific interactions.

With the reuptake blocker type of antidepressants (including TCAs and SRIs), there exists a 100-1,000 fold-magnitude of difference between the concentrations at which selective inhibition of monoamine reuptake and the therapeutic antidepressant effect occurs (Bolo et al., 2000; Torres et al., 2003; Lenkey et al., 2006). The high concentrations required for therapeutic efficacy result in a substantial loss of drug specificity. Within the therapeutic window (e.g. steady state brain concentrations in the low micromolar range), antidepressants affect a number of protein targets, inhibiting numerous types of ion channels and neurotransmitter receptors, which are critical components of neuronal electrical excitability and network activity. Documented interactions of antidepressant drugs include calcium, sodium and potassium channels, as well as serotonergic, adrenergic, dopaminergic, glutamatergic, and cholinergic receptors. The movement of ions through voltage- and ligand-gated channels underlies virtually every aspect of neuronal function action potential generation and synaptic communication being two principle examples. Calcium $\left(\mathrm{Ca}^{2+}\right)$ ions in particular have a critical function as a second messengers in intracellular signalling, regulating numerous neuronal events such as the activation of $\mathrm{Ca}^{2+}$ dependent proteins, the initiation of gene expression, neurite outgrowth, synapse formation, neurotransmitter release and synaptic plasticity (Feng et al., 2002; Xu et al., 2009; Hardingham et al., 1997). As the cardiovascular system similarly depends on ionic influx (i.e. $\mathrm{Ca}^{2+}$ for heart contraction) and neurotransmitter regulation, this opens to the possibility that the non-specific interactions of antidepressant drugs with voltage gated ion channels and neurotransmitter receptors can produce systemic dysregulation, as is seen in the cardiotoxic lethality in TCA overdose. Ultimately, the blind modulation of protein targets by antidepressant drugs contributes to systemic and neuronal side effects that may have devastating consequences.

A fundamental principle of therapeutic intervention is that the derived benefit of the therapy must outweigh the potential risks. Antidepressant medications are readily used as the first-line standard of treatment for the management of MDD, as depression constitutes a substantial personal and economic burden, and the risks associated with untreated depression are substantial (i.e. diminished quality of life, loss of productivity, comorbid diseases, suicide). In accordance with the increasing clinical prevalence of MDD, the use of antidepressant drugs has grown rapidly, being the most commonly prescribed class of medication; SSRIs in particular, with their comparatively innocuous profile of serious adverse effects, are the most widely used type of antidepressant (Olfson \& Marcus, 2009). In light of the potential negative effects arising from the often overlooked non-specific interactions of antidepressant drugs, the limited benefit of antidepressants raises 
considerable grounds for concern. Indeed, despite their widespread use, the risk-benefit ratio of antidepressant drugs is somewhat controversial. In addition to the less-than-optimal response and remission rates resulting from antidepressant pharmacotherapy, the actual pharmacological benefit of antidepressants in the majority of patients - those below the threshold of 'very severe' depression - is largely unfounded. In a patient-level metaanalysis, Fournier et al. (2010) demonstrated that the magnitude of response to antidepressant therapy depends on the baseline depression symptom severity; such that compared to placebo, patients with mild to severe depression do not derive significant benefit from antidepressant pharmacotherapy. Furthermore, these patients with less

\begin{tabular}{|c|c|c|c|}
\hline \multicolumn{2}{|l|}{ Target } & Drug & Reference \\
\hline \multicolumn{4}{|l|}{ Ion channels } \\
\hline \multirow[t]{3}{*}{$\begin{array}{l}\text { Sodium }\left(\mathrm{Na}^{+}\right) \\
\text {channels }\end{array}$} & & $\begin{array}{l}\text { Fluoxetine, } \\
\text { Amitriptyline, } \\
\text { Desipramine, Doxepin }\end{array}$ & Pancrazio et al., 1998 \\
\hline & $\begin{array}{l}\mathrm{Na}_{\mathrm{v}} 1.3, \mathrm{Na}_{\mathrm{v}} 1.4, \\
\mathrm{Na}_{\mathrm{v}} 1.7\end{array}$ & $\begin{array}{l}\text { Duloxetine, Sertraline, } \\
\text { Paroxetine }\end{array}$ & $\begin{array}{l}\text { Wang et al., 2008; } \\
\text { Wang et al., } 2010\end{array}$ \\
\hline & & Citalopram & $\begin{array}{l}\text { Pacher \& Kecskemeti, } \\
2004\end{array}$ \\
\hline \multirow{5}{*}{$\begin{array}{l}\text { Potassium }\left(K^{+}\right) \\
\text {channels }\end{array}$} & HERG & Citalopram & Witchel et al., 2002 \\
\hline & GIRK & $\begin{array}{l}\text { Citalopram, Imipramine, } \\
\text { Amitriptyline }\end{array}$ & Kobayashi et al., 2004 \\
\hline & $\mathrm{K}_{\mathrm{V}} 1.5$ & Citalopram & Lee et al., 2010 \\
\hline & $\mathrm{K}_{\mathrm{V}} 1.1$ & Fluoxetine & Yeung et al., 1999 \\
\hline & $\mathrm{K}_{\mathrm{v} 3.1}$ & Fluoxetine & Sung et al., 2008 \\
\hline \multirow[t]{2}{*}{$\begin{array}{l}\text { Calcium }\left(\mathrm{Ca}^{2+}\right) \\
\text { channels }\end{array}$} & T, N, L- type & Fluoxetine, Citalopram & $\begin{array}{l}\text { Deák et al., 2000; } \\
\text { Witchel et al., } 2002\end{array}$ \\
\hline & P/Q-type & Fluoxetine & Wang et al., 2003 \\
\hline \multicolumn{4}{|c|}{ Neurotransmitter Receptors } \\
\hline \multicolumn{2}{|c|}{$\begin{array}{l}\text { N-Methyl-D-aspartate } \\
(N M D A)\end{array}$} & $\begin{array}{l}\text { Desipramine, } \\
\text { Imipramine }\end{array}$ & $\begin{array}{l}\text { Sernagor et al., 1989; } \\
\text { Reynolds \& Miller, } 1988\end{array}$ \\
\hline \multicolumn{2}{|c|}{ Glycine } & Fluoxetine & Ye et al., 2008 \\
\hline \multirow{2}{*}{\multicolumn{2}{|c|}{$\begin{array}{l}\text { Nicotinic Acetylcholine } \\
(n A C h)\end{array}$}} & Fluoxetine & $\begin{array}{l}\text { García-Colunga et al., } \\
1997\end{array}$ \\
\hline & & Imipramine, & Rana et al., 1993 \\
\hline \multicolumn{2}{|c|}{ Muscarinic Acetylcholine (mACh) } & Imipramine & $\begin{array}{l}\text { Snyder \& Yamamura, } \\
1977\end{array}$ \\
\hline \multicolumn{2}{|c|}{$\begin{array}{c}\text { Serotonin } \\
\left(5-\mathrm{HT}_{3}\right)\end{array}$} & $\begin{array}{l}\text { Fluoxetine, Phenelzine, } \\
\text { Imipramine, Iproniazid }\end{array}$ & Fan et al., 1994 \\
\hline
\end{tabular}

Table 2. Highlight of some of the known ion channel and neurotransmitter receptor targets of antidepressant drugs. 
severe depressions represent the majority of clinical cases, and are frequently excluded from clinical trials establishing antidepressant drug efficacy, where inclusion often requires a minimum baseline symptom severity (Zimmerman et al., 2002). This apparent lack of a meaningful drug response for a large percentage of the MDD patient population tips the balance of the risk-benefit assessment of antidepressant pharmacotherapy, giving rise to the question - could antidepressant therapy be causing more harm than good?

\section{Insights from a single-synapse experimental model}

In addition to its function as a modulatory neurotransmitter in the adult brain, serotonin also plays a role in numerous neurodevelopmental events, including synaptogenesis and the wiring of brain circuits (Gaspar et al., 2003). As antidepressants are known to cross the placental barrier, numerous clinical and animal model studies have investigated the impact of gestational antidepressant exposure, and have identified the occurrence of severe neurodevelopmental birth defects, neuronal network mis-wiring complications, and sustained neurobehavioural effects in association with in utero exposure (Alwan et al., 2007; Xu et al., 2004; Homberg et al., 2009; Oberlander et al., 2009). It is, however, difficult to differentiate between the developmental effects of the maternal mental illness (in clinical studies), excessive levels of serotonin caused by the action of antidepressant drugs, and the non-specific interactions of antidepressants. Identifying the contribution of each of these factors to developmental complications is difficult to assess in the context of complex in vivo models. Similar neurodevelopmental events, such as neurogenesis, synaptogenesis and synaptic plasticity, occur throughout adulthood, where they are believed to underlie adaptive processes such as learning and memory. If the non-specific actions of antidepressant drugs do in fact play a role in the disruption of neuronal architecture and function in the developing brain, then the possibility also exists that the dynamic adult brain may be similarly susceptible, raising new concerns for the potential adverse effects of antidepressant drugs.
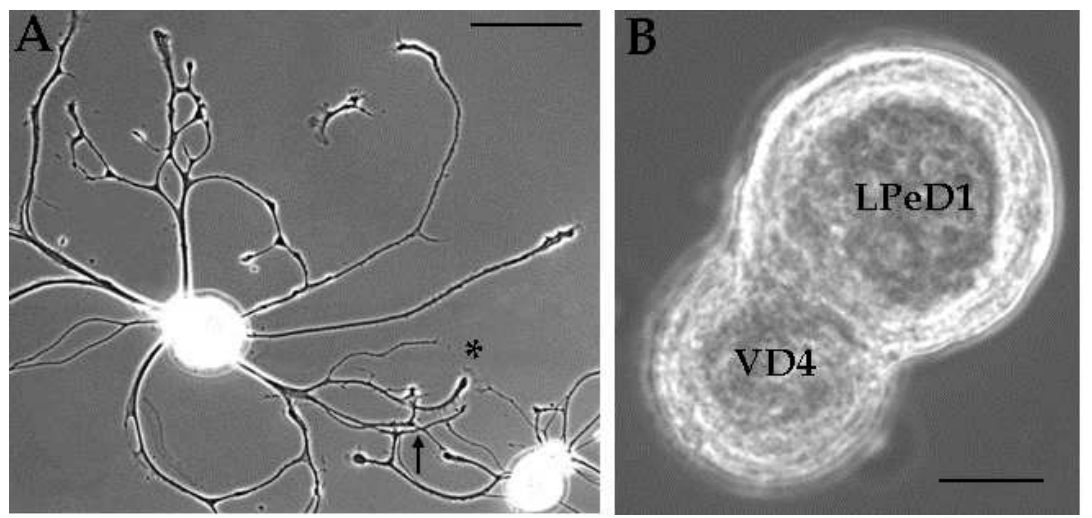

Fig. 1. The in vitro neuronal culture model of Lymnaea stagnalis. A. Neurons cultured in the presence of growth factors extend neurite processes and form synaptic networks with neighboring neurons (arrow). Growth cones (asterisk) actively sense and navigate the environment. Scale bar represents $50 \mu \mathrm{m}$. B. The soma-soma single synapse experimental model. When the somas (cell bodies) of neurons are juxtaposed in culture, synaptogenesis occurs without the reliance on neurite outgrowth. Scale bar represents $25 \mu \mathrm{m}$. 
Our interest in investigating the impact of non-specific antidepressant effects on synapse formation and synaptic function was initiated by the fact that antidepressant drugs indiscriminately inhibit ion channels, and that neurotrophic signalling and synaptic plasticity mechanisms appear to be necessary for the antidepressant response. Our group employs a simple in vitro experimental model to explore the cellular and molecular mechanisms of synapse formation. With the invertebrate model system Lymnaea stagnalis, functionally defined individual neurons with known neurotransmitter phenotype can be isolated and cultured in vitro. In the presence of neurotrophic factors, these neurons regenerate neuronal processes, recapitulate specific synaptic connectivity and establish functional neuronal networks, resembling the developmental events seen in vivo (Syed et al., 1990; Ridgway et al., 1991; Feng et al., 1997). As this model enables the study of individual neurons, synapse formation and synaptic activity at the level of the single synapse, it provides us with a unique opportunity to isolate the impact of the non-specific interactions of antidepressant drugs on neuronal viability, synaptic function, and neurotrophic factor-dependent synaptogenesis.

\subsection{Review of key findings from our comparative evaluation of the neuronal effects of the non-specific actions of two SSRI-type antidepressants}

SSRIs represent the most widely used type of antidepressant medication, and though their action is largely regarded to be specific, or at least the most specific of available medications, there is a growing body of evidence that these compounds indiscriminately affect various aspects of neuronal function, primarily through the non-specific inhibition of ion channels and neurotransmitter receptors. For our investigation, we opted to conduct a comparative analysis of two commonly prescribed SSRI-type antidepressant drugs, fluoxetine and citalopram. Fluoxetine was the first and the most obvious choice for investigation, as it was the first clinically introduced SSRI and is furthermore the most commonly used compound in experimental settings. Within the SSRI class of antidepressants, however, fluoxetine exhibits the lowest degree of selectivity for serotonin reuptake, whereas citalopram is the most selective, and additionally is a more potent inhibitor of serotonin reuptake than fluoxetine (Hyttel, 1994). This lends to the possibility that citalopram may produce an antidepressant effect at lower therapeutic concentrations, thereby reducing the risk of nonspecific inhibitory actions. These pharmacological characteristics lent to the formulation of our hypothesis that different SSRIs would exert characteristic non-specific neuronal side effects, and, because of its lesser selectivity profile, that fluoxetine would exert a more detrimental effect on synaptic physiology than citalopram. Using a combination of intracellular and patch-clamp electrophysiological recordings, calcium imaging, immunocytochemistry and various neuroimaging techniques, we have for the first time demonstrated that clinically-relevant concentrations of fluoxetine, but not citalopram (dosage range up to $5 \mu \mathrm{g} / \mathrm{mL}$; Bolo et al., 2000), exhibit detrimental effects on neurite outgrowth, synapse formation, synaptic transmission and synaptic plasticity, and that the negative effects of fluoxetine on synaptic function involves a direct perturbation of both preand post-synaptic machinery (Xu et al., 2010; Getz et al., 2011).

\subsubsection{Fluoxetine inhibits the initiation of neurite outgrowth and induces growth cone collapse and neurite retraction}

The Effect: Neurite outgrowth is the initial and essential step prior to synapse formation, and is easily and routinely modelled experimentally. We therefore first sought to investigate the 
non-specific neuronal effects of SSRIs by examining their impact on neurite outgrowth. To this end, Lymnaea serotonergic or non-serotonergic neurons were cultured under control conditions (in the presence of growth media containing neurotrophic factors), or in the presence of SSRIs over a therapeutically-relevant dosage range. The neuronal ability to initiate and elongate neurite processes, spread branches and form active growth cones was monitored under these two conditions (Xu et al., 2010). We found that neurons cultured in growth media alone established extensive neurite outgrowth (massive branches with active growth cones), while neurons cultured in the presence of fluoxetine exhibited only minimal branches and shorter processes at lower doses $(<3 \mu \mathrm{g} / \mathrm{mL})$, and no growth at higher concentrations $(>3 \mu \mathrm{g} / \mathrm{mL})$. In neurons that had developed active growth cones, exposure to fluoxetine resulted in the collapse of growth cones within minutes, and the retraction of neurite processes within hours. These negative effects of fluoxetine were observed in Lymnaea neurons regardless of their neurotransmitter phenotype. We also performed a similar investigation using mammalian neurons to determine whether the inhibitory effects of fluoxetine may be attributed to the invertebrate preparation used. Fluoxetine was similarly found to inhibit neurite outgrowth and disrupt neuronal network assembly in both
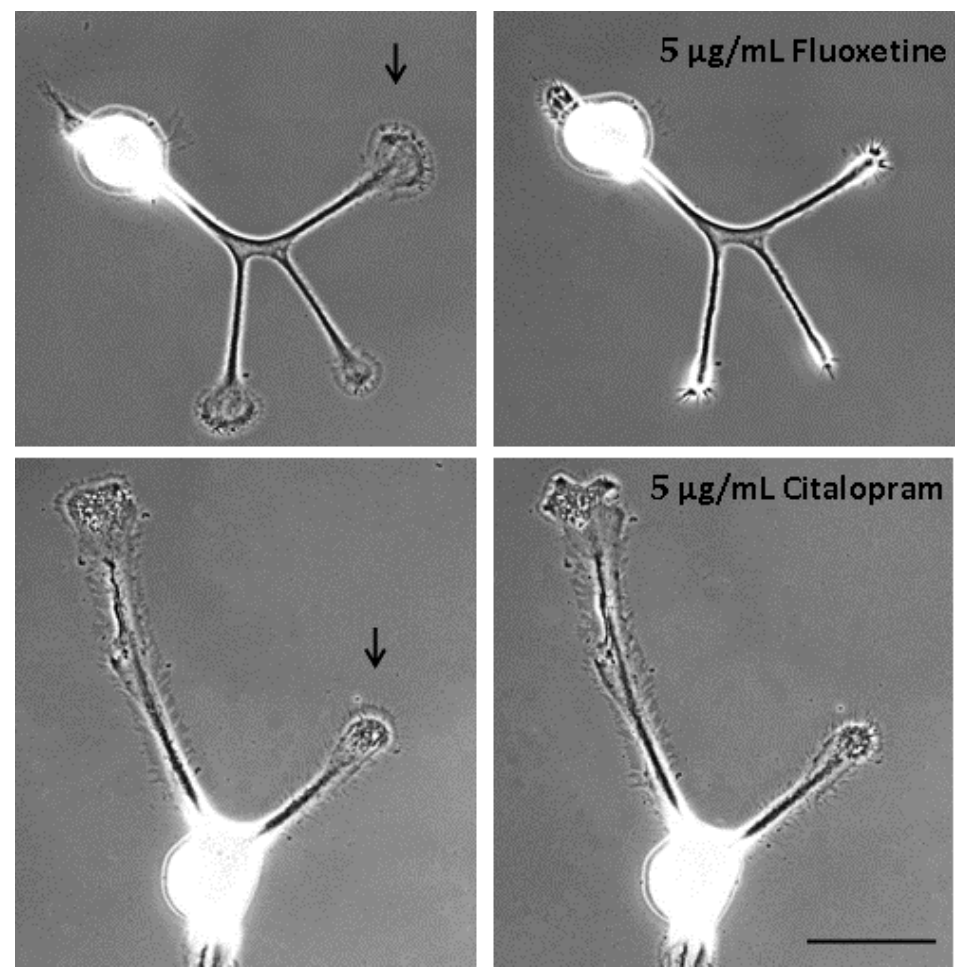

Fig. 2. Acute application of fluoxetine, but not citalopram, causes rapid growth cone collapse and neurite retraction. Lymnaea neurons were cultured in the presence of growth factors and allowed to develop neurite outgrowth with active growth cones (arrow). Within 30 minutes of fluoxetine exposure, all growth cones exhibited collapsed morphology, whereas citalopram application resulted in no discernable detrimental effect. Scale bar represents $50 \mu \mathrm{m}$ 
rat primary cortical neurons and neurohybridoma cells homologous to dorsal root ganglion neurons, thus validating our findings of the inhibitory effects of fluoxetine in Lymnaea neurons. As the negative effect of fluoxetine on neurite outgrowth and growth cone morphology was observed in neurons regardless of vertebrate or invertebrate, serotonergic or non-serotonergic phenotype, these findings suggest that fluoxetine possesses non-specific effects that are independent of its mechanistic action as an SSRI. Interestingly, exposure to citalopram did not exhibit negative effects on neurite outgrowth or growth cone morphology (Getz et al., unpublished observations), suggesting that the negative effects observed for fluoxetine may be a drug-specific property, and not a common feature of the SSRI class of antidepressants.

The Mechanism: Optimal calcium transients in growth cones have been shown to be essential for the regulation of the polymerization and depolymerisation status of cytoskeletal proteins including F-actin, and thus affect growth cone motility and behaviour (Spira et al., 2001; Welnhofer et al., 1999; Henley \& Poo, 2004). In the presence of trophic factors, the growth cones of Lymnaea neurons exhibit small spontaneous $\mathrm{Ca}^{2+}$ transients, and these $\mathrm{Ca}^{2+}$ transients were eliminated within minutes of exposure to fluoxetine ( $\mathrm{Xu}$ et al., 2010). Furthermore, immunocytochemical labeling identified that the fluoxetine-induced inhibition of spontaneous $\mathrm{Ca}^{2+}$ transients and collapse of growth cones was accompanied by a breakdown of the F-actin cytoskeleton. Thus, the perturbation of $\mathrm{Ca}^{2+}$ homeostasis in neuronal growth cones by the non-specific actions of fluoxetine contributes to its detrimental effect on neuronal architecture.

\subsubsection{Fluoxetine, but not citalopram, inhibits synapse formation}

The Effect: Because fluoxetine was found to prevent neurite outgrowth and neuronal network assembly, the use of the soma-soma synapse model, where synapse formation occurs in the absence of neuronal outgrowth, enabled us to investigate how the non-specific effects of SSRIs might affect the development of functional synapses. When paired in a soma-soma configuration, the identified Lymnaea neurons visceral dorsal 4 (VD4) and left pedal dorsal 1 (LPeD1) form a well characterized excitatory cholinergic synapse, in which VD4 functions presynaptically, and LPeD1 functions as the postsynaptic partner. As SSRIs distribute throughout the brain, their actions are not limited to monoaminergic neurons, thus the investigation of the non-specific effects of SSRIs on synaptogenesis and synaptic function in other neuronal systems is warranted. To determine whether SSRI exposure affects synaptogenesis between VD4 and LPeD1, these neurons were cultured in the somasoma configuration in the presence of various concentrations of fluoxetine or citalopram. Simultaneous recordings of presynaptic action potentials (current injection-induced) and postsynaptic potentials (PSPs) were made to determine the effect of SSRI exposure on the incidence of synapse formation, by measuring the percentage of cells that exhibited a functional synapse, and the synaptic strength, by measuring the mean amplitude of PSPs in response to the presynaptic action potential. When cultured in the presence of fluoxetine, neuron pairs exhibited a dose-dependent reduction in both the incidence of synaptogenesis, and, in pairs that did form synapses, a reduction in synaptic efficacy, which was significant at higher concentrations. Interestingly, citalopram had no detrimental effect on either the incidence of synapse formation or synaptic efficacy. Again, these findings lend support to our hypothesis that different SSRIs exhibit characteristic non-specific neuronal effects, and that fluoxetine is more detrimental than citalopram. 


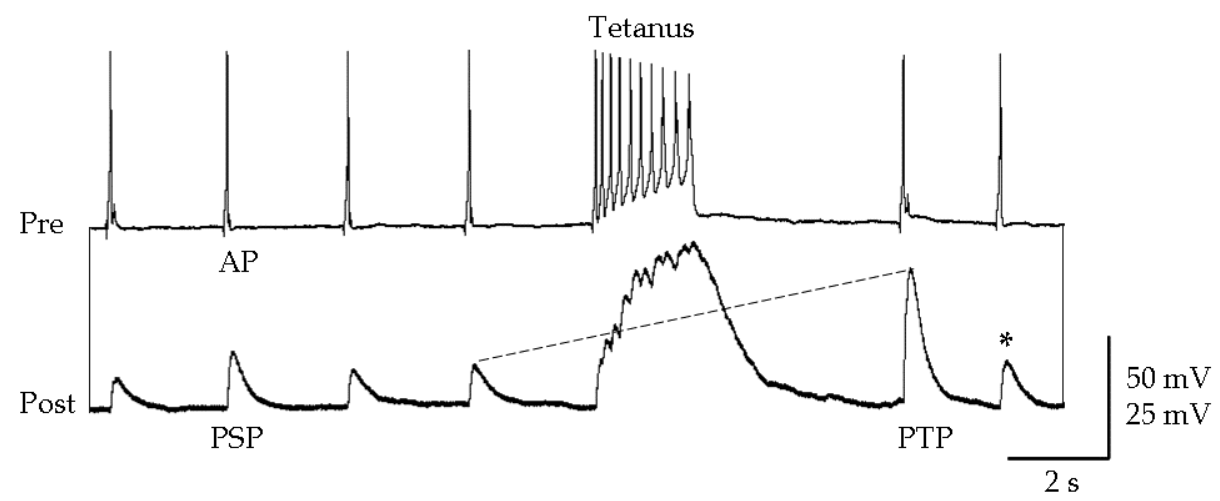

Fig. 3. The simultaneous intracellular electrophysiological recording protocol used in the soma-soma synapse model. Current injection in the presynaptic neuron (pre, VD4) results in the generation of an action potential (AP), which triggers release of neurotransmitter. The efficacy of synaptic transmission can be measured through the amplitude of the resultant excitatory post-synaptic potential (PSP) generated in the postsynaptic neuron (post, LPeD1). Triggering AP burst firing (tetanus) in the presynaptic neuron results in the induction of a use-dependent form of synaptic plasticity, pots-tetanic potentiation (PTP), measured as the ratio of PTP over PSP increase (dotted line). The efficacy of synaptic transmission rapidly returns to baseline values (asterisk), demonstrating the use-dependent characteristic of this type of synaptic plasticity.

The Mechanism: Using the in vitro soma-soma preparation, we have recently found that neurotrophic factor signalling, through triggering $\mathrm{Ca}^{2+}$ influx via voltage-gated calcium channels in the postsynaptic cell and the subsequent expression of excitatory neurotransmitter receptors, is essential for the formation of excitatory synapses ( $\mathrm{Xu}$ et al., 2009). These trophic factor-mediated intracellular $\mathrm{Ca}^{2+}$ oscillations required for excitatory synapse formation were inhibited in the presence of fluoxetine, indicating that fluoxetine prevents the expression of proteins involved in synaptogenesis (Xu et al., 2010). Attesting to this, we found that the expression and synaptic localization of synaptophysin, a synaptic vesicle-associated protein and presynaptic biomarker, were significantly reduced in synapses formed in the presence of fluoxetine, but not citalopram (Getz et al., 2011). Importantly, we also demonstrated that the inhibitory effect of fluoxetine on synapse formation is reversible following prolonged drug washout, and that this recovery is dependent on protein synthesis - that is, new synapses developed following the removal of fluoxetine. Together, these data suggest that fluoxetine, through the non-specific inhibition of $\mathrm{Ca}^{2+}$ signalling and $\mathrm{Ca}^{2+}$-dependent gene expression, affects the assembly of synaptic machinery during synapse formation, and that this contributes to a sustained, albeit reversible impairment of synaptogenesis.

\subsubsection{Acute exposure to fluoxetine and citalopram affects transmission at established synapses}

The Effect: Through the inhibition of ion channel and neurotransmitter receptor activity, the non-specific interactions of SSRIs also have the potential to augment the function of existing synapses. To determine whether neuronal communication at established synapses is 
affected by SSRI exposure, we measured the efficacy of synaptic transmission between VD4LPeD1 soma-soma paired neurons following the acute application of various concentrations of fluoxetine or citalopram. Again, using simultaneous pre- and post-synaptic electrophysiological recordings, the mean amplitude of the PSP provided an indication of synaptic strength, which was recorded before, during and after washout of SSRIs. Following exposure to fluoxetine, the efficacy of synaptic transmission was significantly reduced at all doses examined, and this inhibition was not reversible after a brief washout period. Surprisingly, acute exposure of neuron pairs to citalopram also resulted in a reduction of synaptic transmission efficacy; however, this effect was significant only at the highest concentration evaluated. Moreover, we found that exposure to fluoxetine, and to some extent high concentrations of citalopram, often resulted in the development of presynaptic action potential clamping during burst firing (inability to sustain continuous trains of action potentials), suggesting that the intrinsic membrane properties of the neurons may be affected by both fluoxetine and citalopram exposure, for example, through the non-specific inhibition of the sodium and potassium channels that generate the action potential. Established synapses also exhibit the property of synaptic plasticity, such that synaptic communication is not fixed, but has the capacity to change in response to modulations of neuronal activity patterns. The VD4-LPeD1 synapse exhibits a well characterized usedependent form of short term plasticity known as post-tetanic potentiation (PTP), which is initiated during periods of bursting activity in the presynaptic neuron. Taking this advantage, we investigated whether the inhibition of action potential burst firing resulting from acute SSRI exposure might also affect the occurrence of synaptic plasticity. Interestingly, whereas PTP was not affected by citalopram, exposure to fluoxetine almost completely inhibited the induction of PTP. As both SSRIs were found to affect synaptic transmission at established synapses, yet only fluoxetine affected synaptic plasticity, we postulate that the profiles of inhibitory effects on ion channels and neurotransmitter receptors are unique for these two drugs, and that these drug-specific pharmacological characteristics contribute to the differential neuronal effects seen for fluoxetine and citalopram.

The Mechanism: Synaptic machinery, the components at the synapse that mediate presynaptic neurotransmitter release and the postsynaptic response, must function collectively in order for proper synaptic transmission to occur. Presynaptically, the action potential triggers the influx of $\mathrm{Ca}^{2+}$ through the opening of $\mathrm{N}$-type voltage-gated calcium channels, whereby $\mathrm{Ca}^{2+}$-sensing proteins associated with the synaptic vesicle activate to trigger the release of neurotransmitter into the synaptic cleft. Postsynaptically, released neurotransmitters bind to either ionotropic receptors that produce depolarizing or hyperpolarizing currents in the postsynaptic cell to transfer information between neurons, or metabotropic receptors that activate signalling cascades to affect neuronal activity. Using whole-cell patch clamp recordings, we found that the $\mathrm{Ca}^{2+}$ current in the presynaptic VD4 neuron was significantly reduced after exposure to fluoxetine, but not citalopram, indicating that a direct inhibition of $\mathrm{Ca}^{2+}$ influx through voltage-gated calcium channels contributes to the fluoxetine-mediated inhibition of synaptic transmission. Furthermore, ratiometric $\mathrm{Ca}^{2+}$ imaging revealed that the influx of $\mathrm{Ca}^{2+}$ during action potential burst firing was significantly reduced by both fluoxetine and citalopram, suggesting that a loss of depolarizing driving force (i.e. through the inhibition of sodium and/or potassium channels and the development of action potential clamping) and subsequent indirect reduction in $\mathrm{Ca}^{2+}$ entry is most likely responsible for the citalopram-mediated reduction of synaptic transmission 
(Getz et al., 2011). In Lymnaea neurons, the mechanism underlying the short-term plasticity of PTP has been shown to involve presynaptic $\mathrm{Ca}^{2+}$ entry through voltage-gated calcium channels and subsequent activation of CaMKII, a protein kinase that mediates the effects of intracellular signalling cascades (Luk et al., 2011). This mechanism illuminates how the differential effects of fluoxetine and citalopram on synaptic plasticity can be produced by their respective direct and indirect inhibition of presynaptic $\mathrm{Ca}^{2+}$ entry. Finally, we examined the amplitude of the receptor potential generated in the postsynaptic neuron in response to exogenously applied acetylcholine to determine whether the postsynaptic machinery was also affected by SSRI exposure. Indeed, in the presence of fluoxetine, but not citalopram, the receptor potential was significantly reduced, indicating that the inhibition of neurotransmitter receptors is another mechanism by which the non-specific actions of fluoxetine contributed to the reduction of synaptic transmission efficacy. Ultimately, we find that the negative effect of fluoxetine on synaptic function is attributable to the direct perturbation of numerous components of both pre- and post-synaptic machinery, whereas citalopram exhibits only a minor profile of adverse effects in established synapses, again providing support for the hypothesis that the distinctive auxiliary neuronal effects arise from the characteristic non-specific interactions of SSRIs.

\subsubsection{The inhibitory effects of SSRIs on neuronal function: It all comes down to calcium}

The occurrence of non-specific ion channel and neurotransmitter receptor inhibition by SSRIs is widely acknowledged; however, the potential impact of these effects remains largely disregarded. Taken together, our findings reveal that these non-specific interactions do in fact hold unforeseen consequences for both neurodevelopmental events and synaptic function. Nearly all of the neuronal functions impacted by fluoxetine can be either directly or indirectly attributed to calcium and its critical function as a cytosolic messenger, mediating such diverse neuronal effects as cytoskeletal dynamics, growth cone activity, gene expression, neurotransmitter release, and synaptic plasticity. As citalopram did not directly affect $\mathrm{Ca}^{2+}$ influx through voltage-gated calcium channels, and is additionally associated with a comparatively benign profile of adverse neuronal effects, we propose that the disruption of calcium homeostasis by fluoxetine is the primary causal factor underlying the extensive profile of detrimental neuronal effects attributed to this SSRI.

\begin{tabular}{|l|c|c|c|}
\hline Neuronal Phenomenon & $\mathbf{C a}^{2+}$-dependent? & $\begin{array}{c}\text { Fluoxetine } \\
\text { Inhibition }\end{array}$ & $\begin{array}{c}\text { Citalopram } \\
\text { Inhibition }\end{array}$ \\
\hline Neurite outgrowth & Yes & Yes & No \\
\hline Growth cone dynamics & Yes & Yes & No \\
\hline Synapse formation & Yes & Yes & No \\
\hline Synaptic transmission & Yes & Yes & Yes \\
\hline Synaptic plasticity $(P T P)$ & Yes & Yes & No \\
\hline Presynaptic $I_{C a}$ & Yes & Yes & No \\
\hline
\end{tabular}

Table 3. Summary of the differential effects fluoxetine and citalopram exhibit on neuronal architecture and function. 


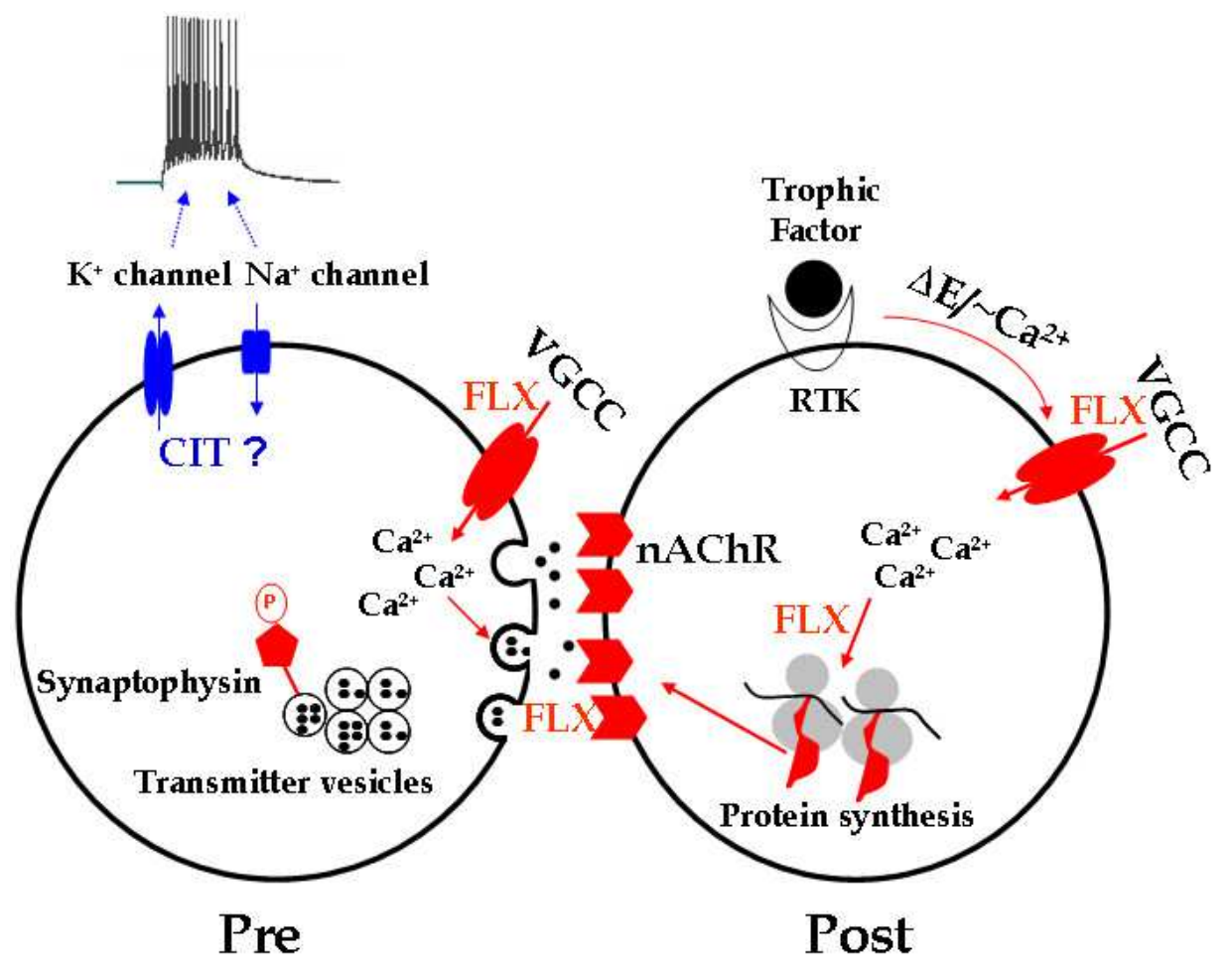

Fig. 4. The proposed mechanisms of non-specific action of SSRIs that contribute to the development of inhibitory effects on neuronal structure and function. Our data suggests that the principle mechanism underlying the fluoxetine-mediated disruption of neuronal function is the inhibition of intracellular calcium signalling. This interferes with numerous neuronal processes including neurotrophic factor signalling through receptor tyrosine kinase (RTK), synaptic protein expression (i.e. synaptophysin, the postsynaptic nACh receptor), synaptogenesis, membrane excitability, and synaptic neurotransmitter release. As citalopram did not exhibit a similar profile of detrimental effects, and did not directly inhibit intracellular calcium influx, we propose that citalopram-mediated disruption of synaptic transmission efficacy may result from the reduction of neuronal excitability, for instance, through the inhibition of the $\mathrm{Na}^{+}$and/or $\mathrm{K}^{+}$channels that contribute to the development of action potentials and the regulation of neuronal excitability. 
While the impact of the promiscuous interactions of antidepressant medications remains largely unaccounted for, we find that one in particular - the modulation of calcium channel activity - can have devastating consequences for neuronal structure and synaptic function. Ultimately, in light of the low clinical efficacy of antidepressant medications and our limited understanding of the mechanism(s) of antidepressant action, the benefits of antidepressant pharmacotherapy, in some instances, may not outweigh the risks.

\section{Conclusions: Looking to the future of antidepressant therapeutics}

After more than half a century of development in the field of antidepressant pharmacotherapy, there has not been a significant improvement in the treatment paradigm or the therapeutic outcome. The last advance came in the 1990's with the introduction of the SRI class of antidepressants, which, to some extent, addressed the need for safer and more tolerable compounds, but left the issues of efficacy and time course of therapeutic action largely unresolved. Assessing the clinical safety of these compounds is complicated by the fact we do not completely understand the mechanism of therapeutic action - making it difficult to differentiate between what may be a necessary effect for therapeutic response and a detrimental effect resulting from non-specific interactions of SRIs with ion channels and neurotransmitter receptors. The limited efficacy profiles, long periods of therapeutic lag, and as we have identified, the potential for inhibitory effects on neuronal function arising from the non-specific interactions of antidepressant medications, underscores the need to develop more selective and more effective therapeutics for the treatment of MDD.

Further development in this field has been hindered by lack of certainty regarding the etiology of depression. Indeed, the complex multifactorial nature of MDD provides no obvious starting points for molecular investigation, and this situation is further confounded by the fact that much of what we currently understand about depression has been gleaned from observing the effects of antidepressant drugs, which themselves appear to act through convoluted and indirect secondary mechanisms. Though slow to gain recognition, the alternative neuroplasticity theory of depression posits that structural changes and neuroplasticity deficits are causative factors underlying MDD, and thus opens to the possibility that these pathways may be targeted directly in attempts to improve therapeutic outcome and perhaps also to reduce the unwanted non-specific effects associated with current antidepressant drugs. An exciting new therapeutic strategy that has made its way into clinical trials involves the use of the psychotropic drug ketamine, which acts as a glutamate NMDA receptor antagonist. Fascinatingly, a single dose of ketamine has been found to produce a rapid (occurring within hours) and sustained (lasting as long as two weeks) antidepressant response through the rapid activation of synaptic plasticity mechanisms (Berman et al., 2000; Li et al., 2010). However, the clinical use of ketamine is limited by its psychotrophic effects and the potential for abuse. Subunit-selective NMDA receptor antagonists that produce an antidepressant response without the development of a psychotropic reaction have more recently been developed and tested clinically, providing an alternate means to achieve the rapid acting antidepressant effects without the side effects and potential complications (Preskorn et al., 2008). As numerous antidepressant drugs have been found to antagonize NMDA receptor 
activity, it is possible that current antidepressant drugs may also be acting through this mechanism - just taking a roundabout and rather ineffectual way of getting there, hence the therapeutic delay and high concentration required for antidepressant response. Herein we find a striking example of the difficulty in interpreting the effects of antidepressant medications without a clear understanding of their mechanism of action, and how this impacts neuronal function.

There is an unmistakable need for a solution to the problems of the high rates of morbidity and mortality present during the extended window of therapeutic inefficacy associated with traditional antidepressants, and the cryptic consequences of their non-specific interactions. The fact that NMDA receptor antagonists produce an antidepressant response with just a single dose, and that this response is sustained beyond the period of drug metabolism and elimination, highlights the potential for this therapeutic strategy to have minimal nonspecific interactions and adverse effects, providing a significant advantage over currently available antidepressant medications. Furthermore, as the onset of antidepressant action of NMDA receptor antagonists is extremely rapid, the limitation of therapeutic lag associated with traditional antidepressants is also addressed. Given the compelling evidence to date, it appears as though NMDA receptor antagonists and the mechanisms of synaptic plasticity may provide a route towards the 'magic-bullet' for depression pharmacotherapy that we have been searching for.

\section{References}

Alwan, S.; Reefhuis, J.; Rasmussen, S.A.; Olney, R.S. \& Friedman, J.M. (2007). Use of selective serotonin-reuptake inhibitors in pregnancy and the risk of birth defects. The New England Journal of Medicine, Vol.356 No.26, (June 2007), pp. 2684-2692, ISSN 0028-4793

Berman, R.M.; Cappiello, A.; Anand, A.; Oren, D.A.; Heninger, G.R.; Charney, D.S. \& Krystal, J.H. (2000). Antidepressant effects of ketamine in depressed patients. Biological Psychiatry, Vol.47, No.4, (February 2000), pp. 351-354, ISSN 0006-3223

Bolo, N.R.; Hodé, Y.; Nédélec, J.F.; Lainé, E.; Wagner, G. \& Macher, J.P. (2000). Brain pharmacokinetics and tissue distribution in vivo of fluvoxamine and fluoxetine by fluorine magnetic resonance spectroscopy. Neuropsychopharmacology, Vol.23, No.4, (October 2000), pp. 428-438, ISSN 0893-133X

Chen, B.; Dowlatshahi, D.; Macqueen, G.M.; Wang, J.F. \& Young, L.T. (2001). Increased hippocampal BDNF immunoreactivity in subjects treated with antidepressant medication. Biological Psychiatry, Vol.50, No.4, pp. 260-265, ISSN 0006-3223

Deák, F.; Lasztóczi, B.; Pacher, P.; Petheö , G.L.; Kecskeméti, V. \& Spät, A. (2000). Inhibition of voltage-gated calcium channels by fluoxetine in rat hippocampal pyramidal cells. Neuropharmacology, Vol.39, No.6, (April 2000), pp. 1029-1036, ISSN 0028-3908

Drevets, W.C. (2001). Neuroimaging and neuropathological studies of depression: implications for the cognitive-emotional features of mood disorders. Current Opinion in Neurobiol, Vol.11, No.2, (April 2001), pp. 240-249, ISSN 0959-4388 
Fan, P. (1994). Effects of antidepressants on the inward current mediated by 5-HT3 receptors in rat nodose ganglion neurons. British Journal of Pharmacology, Vol.112, No.3, (July 1994), pp. 741-744, ISSN 0007-1188

Feng, Z.P.; Grigoriev, N.; Munno, D.; Lukowiak, K.; MacVicar, B.A.; Goldberg, J.I. \& Syed, N.I. (2002). Development of Ca2+ hotspots between Lymnaea neurons during synaptogenesis. Journal of Physiology, Vol.539, No.1, (February 2002), pp. 53-65, ISSN 0022-3751

Feng, Z.P.; Klumperman, J.; Lukowiak, K. \& Syed, N.I. (1997). In vitro synaptogenesis between the somata of identified Lymnaea neurons requires protein synthesis but not extrinsic growth factors or substrate adhesion molecules. The Journal of Neuroscience, Vol.17, No.20, (October 1997), pp. 7839-7849, ISSN 0270-6476

Fournier, J.C.; DeRubeis, R.J.; Hollon, S.D.; Dimidjian, S.; Amsterdam, J.D.; Shelton, R.C. \& Fawcett, J. (2010). Antidepressant drug effects and depression severity. The Journal of the American Medical Association, Vol.303, No.1, (January 2010), pp. 47-53, ISSN 0098-7484

García-Colunga, J.; Awad, J.N. \& Miledi, R. (1997). Blockage of muscle and neuronal nicotinic acetylcholine receptors by fluoxetine (Prozac). Proceedings of the National Academy of Sciences of the United States of America, Vol.94, No.5, (March 1997), pp.2041-2044, ISSN 0027-8424

Gaspar, P.; Cases, O. \& Maroteaux, L. (2003). The developmental role of serotonin: news from mouse molecular genetics. Nature Reviews. Neuroscience, Vol.4, No.12, (December 2003), pp. 1002-1012, ISSN 1471-003X

Getz, A.; Xu, F.; Zaidi, W. \& Syed, N.I. (2011). The antidepressant fluoxetine but not citalopram suppresses synapse formation and synaptic transmission between Lymnaea neurons by perturbing presynaptic and postsynaptic machinery. European Journal of Neuroscience, Vol.34, No.2, (July 2011), pp. 221-234, ISSN 0953-816X

Hardingham, G.E.; Chawla, S.; Johnson, C.M. \& Bading, H. (1997). Distinct functions of nuclear and cytoplasmic calcium in the control of gene expression. Nature Vol.385, No.6613, (January 1997), pp. 260-265, ISSN 0028-0836

Henley, J. \& Poo, M.M. (2004). Guiding neuronal growth cones using Ca2+ signals. Trends inCell Biology, Vol.14, No.6, (June 2004), pp. 320-330, ISSN 0962-8924

Homberg, J.R.; Schubert, D. \& Gaspar, P. (2009). New perspectives on the neurodevelopmental effects of SSRIs. Trends in Pharmacological Science, Vol.31, No.2, (February 2009), pp. 60-65, ISSN 0165-6147

Hyttel, J. (1994). Pharmacological characterization of selective serotonin reuptake inhibitors (SSRIs). International Clinical Psychopharmacology, Vol.9, No.1, (March 1994), pp. 1926, ISSN 0268-1315

Kessler, R.C.; Berglund, P.; Demler, O.; Jun, R.; Merikangas, K.R. \& Walters, E.E. (2005). Lifetime prevalence and age-of-onset distributions of DSM-IV disorders in the national comorbidity survey replication. Archives of General Psychiatry, Vol.62, No.6, (June 2005), pp. 593-602, ISSN 0003-990X

Kobayashi, T.; Washiyama, K. \& Ikeda, K. (2004). Inhibition of G protein-activated inwardly rectifying $\mathrm{K}+$ channels by various antidepressant drugs. Neuropsychopharmacology, Vol.29, No.10, (October 2004), pp. 1841-1851, ISSN 0893-133X 
Krishnan, V. \& Nestler, E.J. (2008). The molecular neurobiology of depression. Nature, Vol.455, No.7215, (October 2008), pp. 894-902, ISSN0028-0836

Lapin, J.P. \& Oxenkrug, G.F. (1969). Intensification of the central serotonergic processes as a possible determinal of the thymoleptic effect. Lancet, Vol.1, No.7586, (January 1969), pp. 132-136, ISSN 0140-6736

Lee, H.M.; Hahn, S.J. \& Choi, B.H. (2010). Open channel block of Kv1.5 currents by citalopram. Acta Pharmacologica Sinica, Vol.31, No.4, (April 2010), pp. 429-435, ISSN 1671-4083

Lenkey, N.; Karoly, R.; Kiss, J.P.; Szasz, B.K.; Vizi, E.S. \& Mike, A. (2006). The mechanism of activity-dependent sodium channel inhibition by the antidepressants fluoxetine and desipramine. Molecular Pharmacology, Vol.70, No.6, (December 2006), pp. 20522063, ISSN 0026-895X

Li, N.; Lee, B.; Liu, R.-J.; Banasr, M.; Dwyer, J.M.; Iwata, M.; Li, X.-Y.; Aghajanian, G. \& Duman, R.S. (2010). mTOR-dependent synapse formation underlies the rapid antidepressant effects of NMDA antagonists. Science, Vol.329, No.5994, (August 2010), pp. 959-964, ISSN 0036-8075

Licinio, J. \& Wong, M.-L. (2005). Depression, antidepressants and suicidality: a critical appraisal. Nature Reviews. Drug Discovery, Vol.4, No.2, (February 2005), pp. 165-171, ISSN 1474-1776

López-León, S.; Janssens, A.C.; González-Zuloeta Ladd, A.M.; Del-Favero, J.; Claes, S.J.; Oostra, B.A. \& van Duijn, C.M. (2008). Meta-analyses of genetic studies on major depressive disorder. Molecular Psychiatry, Vol.13, No.8, (August 2008), pp. 772-785, ISSN 1359-4184

Luk, C.C.; Naruo, H.; Prince, D.; Hassan, A.; Doran, S.A.; Goldberg, J.I. \& Syed, N.I. (2011). A novel form of presynaptic CaMKII-dependent short-term potentiation between Lymnaea neurons. European Journal of Neuroscience, Vol.34, No.4, (August 2011), pp. 848-856, ISSN 0953-816X

Olfson, M. \& Marcus, S.C. (2009). National patterns in antidepressant medication treatment. Archives of General Psychiatry, Vol.66, No.8, (August 2009), pp. 848-856, ISSN 0003990X

Martinowich, K. \& Lu, B. (2008). Interaction between BDNF and serotonin: role in mood disorders. Neuropsychopharmacology Vol.33, No.1, (January 2008), pp. 73-83, ISSN 0893-133X

Maya Vetencourt, J.F.; Sale, A.; Viegi, A.; Baroncelli, L.; De Pasquale, R.; O’Leary, O.F.; Castrén, E. \& Maffei, L. (2008). The antidepressant fluoxetine restores plasticity in the adult visual cortex. Science, Vol.320, No.5874, (April 2008), pp. 385-388, ISSN 0036-8075

Nestler, E.J.; Terwilliger, R.Z. \& Duman, R.S. (1989). Chronic antidepressant administration alters the subcellular distribution of cyclic AMP-dependent protein kinase in rat frontal cortex. Journal of Neurochemistry, Vol.53, No.5, (Novemer 1989), pp. 16441647, ISSN 0022-3042

Nibuya, M.; Nestler, E.J. \& Duman, R.S. (1996). Chronic antidepressant administration increases the expression of cAMP response element binding protein (CREB) in rat 
hippocampus. The Journal of Neuroscience, Vol.16, No.7, (April 1996), pp. 2365-2372, ISSN 0270-6474

Oberlander, T.F.; Gingrich, J.A. \& Ansorge, M.S. (2009). Sustained neurobehavioral effects of exposure to SSRI antidepressants during development: molecular to clinical evidence. Clinical Pharmacology \& Therapeutics, Vol.86, No.6, (December 2009), pp. 672-677, ISSN 0009-9236

Pacher, P. \& Kecskemeti, V. (2004). Cardiovascular side effects of new antidepressants and antipsychotics: new drugs, old concerns? Current Pharmaceutical Design, Vol.10, No.20, (August 2004), pp. 2463-2475, ISSN 1381-6128

Pancrazio, J.J.; Kamatchi, G.L.; Roscoe, A.K. \& Lynch, C. III. (1998). Inhibition of neuronal $\mathrm{Na}+$ channels by antidepressant drugs. The Journal of Pharmacology and Experimental Therapeutics, Vol. 284, No.1, (January 1998), pp. 208-214, ISSN 0022-3565

Pezawas, L.; Meyer-Lindenberg, A.; Goldman, A.L.; Verchinski, B.A.; Chen, G.; Kolachana, B.S.; Egan, M.F.; Mattay, V.S.; Hariri, A.R. \& Weinberger, D.R. (2008). Evidence of biologic epistasis between BDNF and SLC6A4 and implications for depression. Molecular Psychiatry, Vol.13, No.7, (July 2008), pp. 709-716, ISSN 1359-4184

Pittenger, C. \& Duman, R.S. (2008). Stress, depression, and neuroplasticity: a convergence of mechanisms. Neuropsychopharmacology, Vol.33, No.1, (Jan 2008), pp. 88-109, ISSN 0893-133X

Preskorn, S.H.; Baker, B.; Kolluri, S.; Menniti, F.S.; Krams, M. \& Landen, J.W. (2008). An innovative design to establish proof of concept of the antidepressant effects of the NR2B subunit selective N-methyl-D-aspartate antagonist, CP-101,606, in patients with treatment-refractory major depressive disorder. Journal of Clinical Psychopharmacology, Vol.28, No.6, (December 2008), pp. 631-637, ISSN 0271-0749

Rana, B.; McMorn, S.O.; Reeve, H.L.; Wyatt, C.N.; Vaughan, P.F. \& Peers, C. (1993). Inhibition of neuronal nicotinic acetylcholine receptors by imipramine and desipramine. European Journal of Pharmacology, Vol.250, No.2, (December 1993), pp. 247-251, ISSN 0014-2999

Ressler, K.J. \& Mayberg, H.S. (2007). Targeting abnormal neural circuits in mood and anxiety disorders: from the laboratory to the clinic. Nature Neuroscience, Vol.10, No.9, (September 2007), pp. 1116-1124, ISSN 1097-6256

Reynolds, I.J. \& Miller, R.J. (1988). Tricyclic antidepressants block N-methyl-D-aspartate receptors: similarities to the action of zinc. British Journal of Pharmacology, Vol.95, No.1, (September 1988), pp. 95-102, ISSN 0007-1188

Ridgway, R.L.; Syed, N.I.; Lukowiak, K. \& Bulloch, A.G. (1991). Nerve growth factor (NGF) induces sprouting of specific neurons of the snail Lymnaea stagnalis. Journal of Neurobiology, Vol.22, No.4, (June 1991), pp. 377-390, ISSN 0022-3034

Saarelainen, T.; Hendolin, P.; Lucas, G.; Koponen, E.; Sairanen, M., MacDonald, E.; Agerman, K.; Haapasalo, A.; Nawa, H.; Aloyz, R.; Ernfors, P. \& Castrén, E. (2003). Activation of the TrkB neurotrophin receptor is induced by antidepressant drugs and is required for antidepressant-induced behavioural effects. The Journal of Neuroscience, Vol.23, No.1, (January 2003), pp. 349-357, ISSN 0270-6474

Santarelli, L.; Saxe, M.; Gross, C.; Surget, A.; Battaglia, F.; Dulawa, S.; Weisstaub, N.; Lee, J.; Duman, R.; Arancio, O.; Belzung, C. \& Hen, R. (2003). Requirement of hippocampal 
neurogenesis for the behavioural effects of antidepressants. Science, Vol.301, No.5634, (August 2003), pp. 805-809, ISSN 0036-8075

Schildkraut, J.J. (1965). The catecholamine hypothesis of affective disorders: a review of supporting evidence. The American Journal of Psychiatry, Vol.122, No.5, (November 1965), pp. 509-522, ISSN 0002-953X

Sernagor, E.; Kuhn, D., Vyklicky, L. Jr. \& Mayer, M.L. (1989). Open channel block of NMDA receptor responses evoked by tricyclic antidepressants. Neuron, Vol. 2, No.3, (March 1989), pp. 1221-1227, ISSN 0896-6273

Shimizu, E.; Hashimoto, K.; Okamura, N.; Koike, K.; Komatsu, N.; Kumakiri ,C.; Nakazato, M.; Watanabe, H.; Shinoda, N., Okada, S. \& Iyo, M. (2003). Alterations of serum levels of brain-derived neurotrophic factor (BDNF) in depressed patients with or without antidepressants. Biological Psychiatry, Vol.54, No.1, (July 2003), pp. 70-75, ISSN 0006-3223

Snyder, S.H. \& Yamamura, H.I. (1977). Antidepressants and the muscarinic acetylcholine receptor. Archives of General Psychiatry, Vol.34, No.2, (February 1977), pp. 236-239, ISSN 0003-990X

Spira, M.E.; Oren, R.; Dormann, A.; Ilouz, N. \& Lev, S. (2001). Calcium, protease activation, and cytoskeleton remodelling underlie growth cone formation and neuronal regeneration. Cellular and Molecular Neurobiology, Vol.21, No.6, (December 2001), pp. 591-604, ISSN 0272-4340

Sullivan, P.F.; Neale, M.C. \& Kendler, K.S. (2000). Genetic epidemiology of major depression: review and meta-analysis. The American Journal of Psychiatry, Vol.157, No.10, (October 2000), pp. 1552-1562, ISSN 0002-953X

Sung, M.J.; Ahn, H.S.; Hahn, S.J. \& Sung, H.C. (2008). Open channel block of Kv3.1 currents by fluoxetine. Journal of Pharmacological Sciences, Vol.106, No.1, (January 2008), pp. 38-45, ISSN 1347-8613

Syed, N.I.; Bulloch, A.G. \& Lukowiak, K. (1990). In vitro reconstruction of the respiratory central pattern generator of the mollusc Lymnaea. Science, Vol.250, No.4978, (October 1990), pp. 282-285, ISSN 0036-8075

Tao, X.; Finkbeiner, S.; Arnold, D.B.; Shaywitz, A.J. \& Greenberg, M.E. (1998). Ca2+ influx regulates BDNF transcription by a CREB family transcription factor-dependent mechanism. Neuron, Vol.20, No.4, (April 1998), pp.709-726, ISSN 0896-6273

Thase, M.E. (2011). Antidepressant combinations: widely used, but far from empirically validated. Canadian Journal of Psychiatry, Vol.56, No.6, (June 2011), pp. 317-323, ISSN 0706-7437

Thase, M.E.; Haight, B.R.; Richard, N.; Rockett, C.B.; Mitton, M.; Modell, J.G.; VanMeter, S.; Harriett, A.E. \& Wang, Y. (2005). Remission rates following antidepressant therapy with bupropion or selective serotonin reuptake inhibitors: a meta-analysis of original data from 7 randomized controlled trials. The Journal of Clinical Psychiatry, Vol.66, No.8, (August 2005), pp. 974-981, ISSN 0160-6689

Torres, G.E.; Gainetdinov, R.R. \& Caron, M.G. (2003). Plasma membrane monoamine transporters: structure, regulation and function. Nature Reviews. Neuroscience, Vol.4, No.1, (January 2003), pp. 13-25, ISSN 1471-003X 
Trivedi, M.H.; Rush, A.J.; Wisniewski, S.R.; Nierenberg, A.A.; Warden, D.; Ritz, L.; Norquist, G.; Howland, R.H.; McGrath, P.J.; Shores-Wilson, K.; Biggs, M.M.; Balasubramani, G.K.; Fava, M. \& STAR*D Study Team. (2006). Evaluation of outcomes with citalopram for depression using measurement-based care in STAR ${ }^{*}$ : implications for clinical practice. The American Journal of Psychiatry, Vol.163, No.1, (January 2006), pp. 28-40, ISSN 0002-953X

Wang, G.K.; Mitchell, J. \& Wang, S.Y. (2008). Block of persistent late Na+ currents by antidepressant sertraline and paroxetine. The Journal of Membrane Biology, Vol.222, No.2, (March 2008), pp. 79-90, ISSN 0022-2631

Wang, S.J.; Su, C.F. \& Kuo, Y.H. (2003). Fluoxetine depresses glutamate exocytosis in the rat cerebrocortical nerve terminals (synaptosomes) via inhibition of P/Q-type Ca2+ channels. Synapse, Vol.48, No.4, (June 2003), pp. 170-177, ISSN 0887-4476

Wang, S.-Y.; Calderon, J. \& Kuo Wang, G. (2010). Block of neuronal Na+ channels by antidepressant duloxetine in a state-dependent manner. Anesthesiology, Vol.113, No.3, (September 2010), pp. 655-665, ISSN 0003-3022

Welnhofer, E.A.; Zhao, L. \& Cohan C.S. (1999). Calcium influx alters actin bundle dynamics and retrograde flow in Helisoma growth cones. The Journal of Neuroscience, Vol.19, No.18, (September 1999), pp. 7971-7982, ISSN 0270-6474

Witchel, H.J.; Pabbathi, V.K.; Hofmann, G.; Paul, A.A. \& Hancox, J.C. (2002). Inhibitory actions of the selective serotonin re-uptake inhibitor citalopram on HERG and ventricular L-type calcium currents. FEBS Letters, Vol.512, No.1-3, (February 2002), pp. 59-66, ISSN 0014-5793

Xu, Y.; Sari, Y. \& Zhou, F.C. (2004). Selective serotonin reuptake inhibitor disrupts organization of thalamocortical somatosensory barrels during development. Developmental Brain Research, Vol.150, No.2, (June 2004), pp. 151-161, ISSN 01653806

Xu, F.; Hennessy, D.A.; Lee, T.K. \& Syed, N.I. (2009) Trophic factor-induced intracellular calcium oscillations are required for the expression of postsynaptic acetylcholine receptors during synapse formation between Lymnaea neurons. The Journal of Neuroscience, Vol.29, No.7, (February 2009), pp. 2167-2176, ISSN 0270-6474

Xu, F.; Luk, C.; Richard, M.P.; Zaidi, W.; Farkas, S.; Getz, A.; Lee, A.; van Minnen, J. \& Syed, N.I. (2010). Antidepressant fluoxetine suppresses neuronal growth from both vertebrate and invertebrate neurons and perturbs synapse formation between Lymnaea neurons. European Journal of Neuroscience, Vol. 31, No.6, (March 2010), pp. 994-1005, ISSN 0953-816X

Ye, Z.Y.; Lu, Y.G.; Sun, H.; Cheng, X.P.; Xu, T.L. \& Zhou, J.N. (2008). Fluoxetine inhibition of glycine receptor activity in rat hippocampal neurons. Brain Research, Vol.1239, (November 2008), pp. 77-84, ISSN 0006-8993

Yeung, S.Y.; Millar, J.A. \& Mathie, A. (1999). Inhibition of neuronal KV potassium currents by the antidepressant drug, fluoxetine. British Journal of Pharmacology, Vol.128, No.7, (December 1999), pp. 1609-1615, ISSN 0007-1188

Zimmerman, M.; Posternak, M.A. \& Chelminski, I. (2002). Symptom severity and exclusion from antidepressant efficacy trials. Journal of Clinical Psychopharmacology, Vol.22, No.6, (December 2002), pp. 610-614, ISSN 0271-0749 
Zou, K.; Deng, W.; Li, T.; Zhang, B.; Jiang, L.; Huang, C.; Sun, X. \& Sun, X. (2010). Changes of brain morphometry in first-episode, drug-naïve, non-late-life adult patients withmajor depression: an optimized voxel-based morphometry study. Biological Psychiatry, Vol.67, No.2, (January 2010), pp. 186-188, ISSN 0006-3223 


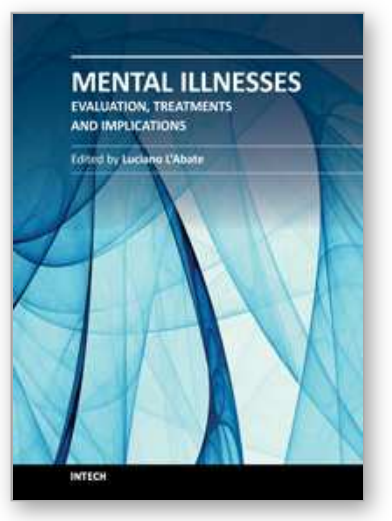

\author{
Mental IIInesses - Evaluation, Treatments and Implications \\ Edited by Prof. Luciano LAbate
}

ISBN 978-953-307-645-4

Hard cover, 476 pages

Publisher InTech

Published online 13, January, 2012

Published in print edition January, 2012

In the book "Mental Illnesses - Evaluation, Treatments and Implications" attention is focused on background factors underlying mental illness. It is crucial that mental illness be evaluated thoroughly if we want to understand its nature, predict its long-term outcome, and treat it with specific rather than generic treatment, such as pharmacotherapy for instance. Additionally, community-wide and cognitive-behavioral approaches need to be combined to decrease the severity of symptoms of mental illness. Unfortunately, those who should profit the most by combination of treatments, often times refuse treatment or show poor adherence to treatment maintenance. Most importantly, what are the implications of the above for the mental health community? Mental illness cannot be treated with one single form of treatment. Combined individual, community, and socially-oriented treatments, including recent distance-writing technologies will hopefully allow a more integrated approach to decrease mental illness world-wide.

\title{
How to reference
}

In order to correctly reference this scholarly work, feel free to copy and paste the following:

Angela Getz, Fenglian Xu and Naweed Syed (2012). Antidepressant Pharmacotherapy - Do the Benefits Outweigh the Risks?, Mental Illnesses - Evaluation, Treatments and Implications, Prof. Luciano LAbate (Ed.), ISBN: 978-953-307-645-4, InTech, Available from: http://www.intechopen.com/books/mental-illnessesevaluation-treatments-and-implications/antidepressant-pharmacotherapy-do-the-benefits-outweigh-the-risks-

\section{INTECH}

open science | open minds

\section{InTech Europe}

University Campus STeP Ri

Slavka Krautzeka 83/A

51000 Rijeka, Croatia

Phone: +385 (51) 770447

Fax: +385 (51) 686166

www.intechopen.com

\section{InTech China}

Unit 405, Office Block, Hotel Equatorial Shanghai

No.65, Yan An Road (West), Shanghai, 200040, China

中国上海市延安西路65号上海国际贵都大饭店办公楼 405 单元

Phone: +86-21-62489820

Fax: +86-21-62489821 
(C) 2012 The Author(s). Licensee IntechOpen. This is an open access article distributed under the terms of the Creative Commons Attribution 3.0 License, which permits unrestricted use, distribution, and reproduction in any medium, provided the original work is properly cited. 